\title{
Pengaruh Pengelolaan Wakaf terhadap Tingkat Produktivitas pada Lembaga Wakaf
}

\author{
Salsabila Pratiwi*, Sri Fadilah \\ Prodi Akuntansi, Fakultas Ekonomi dan Bisnis, Universitas Islam Bandung, \\ Indonesia.
}

*tiwi799@gmail.com, srifadilah03@gmail.com

\begin{abstract}
This study was conducted to determine the effect of waqf management on the level of productivity in waqf institutions. The nature of this research is quantitative. The research method used is a survey method with a quantitative approach. To test the data in the study using simple regression analysis. The data source used is the primary data source which is carried out by distributing online questionnaires to waqf institutions in Greater Bandung. The sampling technique used in this study is simple random sampling, with a total of 31 respondents from waqf institutions in Bandung Raya. It has 20 statements, each statement for the waqf management variable consists of 11 statements and 9 statements for the productivity level variable at the waqf institution. The results obtained from this study indicate that waqf management has a significant effect on the level of productivity in waqf institutions. That is, the better the nazhirs in implementing waqf management in waqf institutions, the results of the productivity level obtained at waqf institutions will also be good.
\end{abstract}

Keywords: Waqf management and Productivity level.

Abstrak. Penelitian ini dilakukan untuk mengetahui pengaruh pengelolaan wakaf terhadap tingkat produktivitas pada lembaga wakaf. Sifat dari penelitian ini kuantitatif. Metode penelitian yang digunakan yaitu metode survey dengan pendekatan kuantitatif. Untuk pengujian data pada penelitian menggunakan analisis regresi sederhana. Sumber data yang digunakan yaitu sumber data primer yang dilakukan penyebaran kuesioner online kepada lembaga - lembaga wakaf yang ada di Bandung raya. Teknik pengambilan sampel yang digunakan pada penelitian yaitu simple random sampling, dengan jumlah 31 responden dari lembaga wakaf di Bandung Raya. Memiliki 20 pernyataan, yang masing- masing pernyataan untuk variabel pengelolaan wakaf terdiri dari 11 pernyataan dan 9 pernyataan untuk variabel tingkat produktivitas pada lembaga wakaf. Hasil yang didapat dari penelitian ini menunjukkan pengelolaan wakaf berpengaruh secara signifikan pada tingkat produktivitas pada lembaga wakaf. Artinya, semakin baik para nazhir menerapkan pengelolaan wakaf pada lembaga wakaf maka hasil tingkat produktivitas yang didapat pada lembaga wakaf juga akan baik pula.

Kata Kunci: Pengelolaan Wakaf, Tingkat Produktivitas. 


\section{A. Pendahuluan}

Negara Indonesia merupakan salah satu negara terbesar mayoritas muslim. Wakaf merupakan salah satu dari kegiatan kemanusiaan lainnya dalam perekonomian Islam (Wijaya, 2015:1). Potensi wakaf di negara Indonesia cukup besar karena mayoritas penduduk adalah muslim. Di Indonesia penduduk muslim terbilang cukup besar sekitar 229,62 juta jiwa( Globalreligiusfuture). Potensi wakaf dapat dimanfaatkan untuk mengurangi kemiskinan yang terjadi pada saat ini(Ananto Triwibowo,2020:124). Wakaf di Indonesia dikelola oleh badan atau lembaga yang mengerti mengenai pengelolaan wakaf, yang hasil atau ouput berupa uang, tanah dan sebagainya dapat dimanfaatkan untuk masyarakat. Lembaga wakaf tidak hanya dituntut profesional dalam mengelola harta, tetapi juga mengikuti aturan (Sri Fadilah, 2015:358). Wakaf sudah diatur dalam perundang- undangan pada tahun 2004 tentang wakaf. Dan standar yang dipakai untuk wakaf yaitu SAK 112 dengan adanya standar keuangan dapat membantu dan mengetahui alur wakaf yang dikelola secara baik dan benar sehingga hasil yang dari pengelolaan itu sendiri dapat optimal

Tingkat produktivitas wakaf di Indonesia cukup rendah karena penurunan kemiskinan merupakan salah satu tolak ukur keberhasilan dari tujuan wakaf mengentaskan kemiskinan dan kesenjangan nasional. Jumlah penduduk miskin terus bertambah dari tahun ke tahun. Penduduk miskin di Indonesia mengalami peningkatan pada tahun 2020 sebesar 0,56\% terhadap pada tahun 2019 hal ini tercatat pada badan pusat statistik dan pada tahun yang sama yaitu tahun 2019 dari bulan Maret ke bulan September mengalami kenaikan 0,37\% (Badan Pusat Statistik).

Rendahnya hasil dari tingkat produktivitas pada lembaga wakaf karena kemampuan dari pengelolaan wakaf yang kurang. Dan faktor- faktor yang mempengaruhi tingkat produktivitas menurut (Sumarsono Sonny:2003) manajemen atau pengelolaan. Hal ini menujukkan tingkat produktivitas dipengaruhi oleh pengelolaan. Pengertian dari pengelolaan proses melakukan kegiatan secara teratur dengan menggerakkan kemampuan seseorang untuk mencapai tujuan yang ditetapkan (Kamus Besar Bahasa Indonesia). Hal ini menjadikan pengelolaan akan mempengaruhi hasil dari semua kegiatan yang akan dilaksanakan oleh organisasi untuk mencapai tujuan.

Fenomena yang terjadi pada bulan September tahun 2020 tepatnya pada tanggal 14 September 2020 Wakil Presiden Indonesia meminta agar pengelolan wakaf dilakukan secara profesional. Nazhir ( pengelola wakaf ) dituntut melakukan pengelolaan wakaf yang lebih berinovasi dari sisi pengumpulan dan pemanfaatan wakaf. Dan Wapres RI yaitu Maaruf Amin mengatakan tingkat produktivitas pada lembaga wakaf dapat meningkat apabila pengelolaan wakaf dilakukan secara profesional.

Pada tahun 2019 bedasarkan data yang didapatkan dua ribu triliun rupiah besarnya aset wakaf, aset wakaf yang dimanfaatkan sekitar empat ratus miliar rupiah dari potensi wakaf berkisar Rp 188 triliun pertahun. Hal ini menujukkan bahwa pengelolaan wakaf belum sepenuhnya baik dan benar. Tanah wakaf pada tahun 2019 bedasarkan data Kementrian ATR/ BPN bidang tanah wakaf yang telah bersetifikat 134.237 dan luas tanah wakaf Indonesia yang bersetifikat 111.481 .173 meter persegi.

Tanah wakaf baik yang belum tersertifikasi maupun yang sudah tersertifikasi pengelolan terhadap tanah wakaf tersebut belum maksimal dikarenakan kurangnya pemahaman terhadap pengelolaan tanah wakaf tersebut. Apabila tanah wakaf dapat dimanfaatkan dengan baik akan menghasilkan keuntungan finansial dan meningkatkan tingkat produktivitas pada lembaga wakaf. Hasil yang diperoleh lembaga wakaf terhadap pengelolaan wakaf akan direalisasikan kepada masyarakat. Namun, pengelolaan tanah wakaf masih minim.

Bedasarkan fenomena- fenomena diatas, identifikasi masalah sebagai berikut :

1. Bagaimana pengelolaan wakaf ?

2. Bagaimana tingkat produktivitas pada lembaga wakaf

3. Bagaimana pengaruh pengelolaan wakaf terhadap tingkat produktivitas di lembaga wakaf? 
Tujuan dilakukan penelitian ini, berikut uraian dibawah:

1. Untuk mengetahui bagaimana pengelolaan wakaf.

2. Untuk mengetahui bagaimana tingkat produktivitas pada lembaga wakaf.

3. Untuk mengetahui bagaimana pengaruh pengelolaan wakaf terhadap tingkat produktivitas pada lembaga wakaf.

\section{B. Metodologi}

Objek penelitian yang digunakan pada penelitian ini adalah pengelolaan wakaf dan tingkat produktivitas pada lembaga wakaf. Metode penelitian menggunakan metode survey dengan pendekatan kuantitatif. Sumber data yang digunakan pada penelitian sumber data primer dan teknik pengumpulan data pada penelitian ini kuesioner yang sumber langsung diperoleh dari responden tanpa perantara orang ketiga. Populasi pada penelitian ini adalah 10 lembaga wakaf di Bandung raya dan teknik sample yang digunakan simple random sampling.

\section{Pembahasan dan Diskusi}

\section{Hasil Analisi Regresi Linear Sederhana}

Berikut hasilnya menggunakan aplikasi SPSS pengaruh pengelolaan wakaf terhadap tingkat produktivitas pada lembaga wakaf.

Tabel 1. Hasil Analisis Regresi Sederhana

\begin{tabular}{|c|c|c|c|c|c|c|}
\hline \multicolumn{7}{|c|}{ Coefficients $^{\mathrm{a}}$} \\
\hline & & \multicolumn{2}{|c|}{$\begin{array}{l}\text { Unstandardized } \\
\text { Coefficients }\end{array}$} & $\begin{array}{l}\text { Standardized } \\
\text { Coefficients }\end{array}$ & \multirow[b]{2}{*}{$\mathrm{t}$} & \multirow[b]{2}{*}{ Sig. } \\
\hline \multicolumn{2}{|c|}{ Variabel } & $\mathrm{B}$ & Std. Error & Beta & & \\
\hline \multirow[t]{2}{*}{1} & Konstanta & 5,844 & 5,151 & & 1,135 & 0,266 \\
\hline & $\begin{array}{l}\text { Pengelolaan } \\
\text { wakaf }\end{array}$ & 0,629 & 0,158 & 0,594 & 3,975 & 0,000 \\
\hline
\end{tabular}

Persamaan regresi linear sederhana dari tabel diatas

TP = 5,844 +0,629 PW

Keterangan :

TP : Tingkat Produktivitas

PW : Pengelolaan Wakaf

Persamaan di atas dapat diartikan sebagai berikut:

1. $\alpha=5,844$ Artinya apabila tidak ada kenaikan dari varibel pengelolaan wakaf, sehingga nilai variabel tingkat produktivititas sebesar 5,844.

2. Koesifisien sebesar 0,629 menyatakan setiap ada penambahan satu nilai pada pengelolaan wakaf maka akan memberikan kenaikan nilai pada tingkat produktivitas sebesar 0,629. Karena bertanda adanya pengaruh dapat disimpulkan bahwa pengelolaan wakaf berpengaruh pada tingkat produktivitas.

3. Nilai Beta menunjukkan besar pengaruh pengelolaan wakaf terhadap tingkat produktivitas, nilai beta tersebut adalah 0,594 .

\section{Kesimpulan}

Bedasarkan hasil penelitian dari pengaruh pengelolaan wakaf terhadap tingkat produktivitas pada lembaga wakaf di Bandung Raya dapat disimpulkan, bahwa hasil pengujian dan analisis menunjukkan pengelolaan wakaf berpengaruh signifikan pada tingkat produktivitas pada lembaga wakaf. Artinya, semakin baik para nazhir menerapkan pengelolaan wakaf dengan baik maka hasil tingkat produktivitas pada lembaga wakaf juga akan baik pula. 


\section{Daftar Pustaka}

[1] Fadilah,S.2015. Going Concern: An Implementation inWaqf Institutions (Religious Charitable Endowment). Procedia-Social and Behavioral Sciences, 211, 356-363.

[2] Fadilah, S.,Maemunah, M.,Hernawati, N.,\& Kuntorini, R,S.2018. Implementasi Good Zakat Governance Pada BAZNAZ Se-Bandung Raya. Jurnal Kajian Akuntansi UNISBA Volume 19 No. 2

[3] Gomes, Faustino Cardoso. 2003. Manajemen Sumber Daya Manusia. Yogyakarta: Andi Offset.

[4] Nazsir, Nasrullah.2003. Good Governance: Mediator Vol 4 No.1

[5] Payaman J. Simanjuntak .2011.Manajemen Evaluasi Kinerja .Edisi 3. Jakarta. Fakutas UI

[6] Sedarmayanti. 2001. Produktivitas Kerja Karyawan. Bandung : Cv Mandar Maju

[7] Simamora, Henry. 2004. Manajemen Sumber Daya Manusia. Yogyakarta: STIE YKPN, Yogyakarta

[8] Suhadi, Imam, 2002, Wakaf Untuk Kesejahteraan Umat, (Disertasi diterbitkan buku), Yogjakarta: PT. Dana Bhakti Prima Yasa

[9] Sumarsono, Sonny. 2003. Ekonomi Manajemen Sumber Daya Manusia dan Ketenagakerjaan. Yogyakarta : Graha Ilmu

[10] Tjokroamidjojo, Bintoro. 2014. Mewujudkan Good Governance Melalui Pelayanan Publik. Yogyakarta:UGM Press.

[11] Tribowo, Ananto. 2020. Penerapan Prinsip- Prinsip Good Corporate Governance dalam Pengelolaan Wakaf Tunai Pada Badan Wakaf Uang Tunai MUI Yogyakarta : Tapis, Jurnal Penelitian Ilmiah Vol 4 No. 1

[12] Wijaya,Intan.2015.Pengelolaan dan Pelaporan Aset Wakaf pada Lembaga Wakaf di Indonesia. Semarang: repository Universitas Diponegoro 